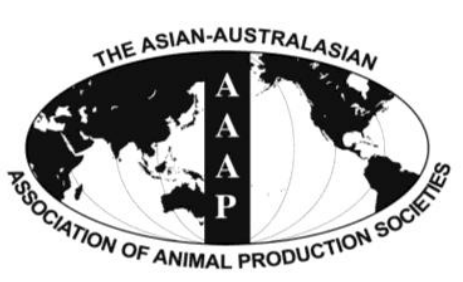

Open Access

Asian Australas. J. Anim. Sci.

Vol. 28, No. 6 : 840-846 June 2015

http://dx.doi.org/10.5713/ajas.14.0849

www.ajas.info

pISSN 1011-2367 elSSN 1976-5517

\title{
Effects of Dietary Corticosterone on Yolk Colors and Eggshell Quality in Laying Hens
}

\author{
Yeon-Hwa Kim ${ }^{1,2}$, Jimin Kim ${ }^{1,2,3}$, Hyung-Sook Yoon ${ }^{1,2}$, and Yang-Ho Choi ${ }^{2,3, *}$ \\ ${ }^{1}$ Division of Applied Life Sciences (BK21 Plus program), Gyeongsang National University, Jinju 660-701, Korea
}

\begin{abstract}
The objective of this study was to investigate the effects of dietary corticosterone on egg quality. For 2 weeks hens received either control or experimental diet containing corticosterone at $30 \mathrm{mg} / \mathrm{kg}$ diet. Feed intake and egg production were monitored daily, and body weight measured weekly. Egg weights and egg quality were measured daily. Corticosterone treatment resulted in a remarkable increase in feed intake and sharp decrease in egg production compared with control $(\mathrm{p}<0.05)$ whereas body weight remained unchanged. Decreased albumen height, but no changes in egg weight, led to decreased Haugh unit ( $\mathrm{p}<0.05)$. Corticosterone caused elevated eggshell thickness $(\mathrm{p}<0.05)$ without altering weight and strength, suggesting possible changes in shell structure. Yolk color and redness were increased by corticosterone $(\mathrm{p}<0.05)$ but lightness and yellowness were either not changed or inconsistent over the time period of measurements. Increased concentrations in plasma were also found for corticosterone, glucose, cholesterol, creatinine, uric acid, albumin, aspartate aminotransferase, creatine kinase, lactate dehydrogenase, total protein, and amylase $(\mathrm{p}<0.05)$, suggesting that corticosterone increased protein breakdown, renal dysfunctions and pancreatitis. Together, the current results imply that dietary corticosterone affects egg quality such as yolk colors and shell thickness, in addition to its effects on feed intake and egg production. (Key Words: Laying Hens, Egg Quality, Stress, Corticosterone, Yolk Colors, Shell Thickness)
\end{abstract}

\section{INTRODUCTION}

Chickens are exposed to many external factors in the course of their life. Factors that may induce stress responses include stocking density, temperature, transport, feed restriction, feed contamination, fear and diseases (Nicol et al., 2006; Thaxton et al., 2006; Delezie et al., 2007), which can activate the hypothalamic-pituitary-adrenal axis to enhance the release of glucocorticoids from the adrenal gland (Carsia and Harvey, 2000). One of the glucocorticoids is corticosterone that is the primary stress hormone in avian species, including chickens, and stimulates gluconeogenesis to provide the body with more energy when birds encounter stressful situations (Carsia and Harvey, 2000).

\footnotetext{
* Corresponding Author: Yang-Ho Choi. Tel: +82-55-772-1946, Fax: +82-55-772-1949, E-mail: yhchoi@gnu.ac.kr

${ }^{2}$ Department of Animal Science, Gyeongsang National University, Jinju 660-701, Korea.

${ }^{3}$ Institute of Agriculture and Life Sciences, Gyeongsang National University, Jinju 660-701, Korea.

Submitted Nov. 3, 2014; Revised Dec. 23, 2014; Accepted Jan. 19, 2015
}

Corticosterone has been frequently used as a tool of inducing stress responses to study the effects of stress in chickens. For example, daily administrations of corticosterone cause responses such as increased feed and water consumptions, reduced energy absorptive efficiency, suppressed growth rate, enhanced proteolysis and gluconeogenesis in broilers (Siegel and Van Kampen, 1984; Lin et al., 2004a). Similar results were found in young male chicks treated with cortisol showing decreased growth rate and increased muscle breakdown (Bellamy and Leonard, 1965). With reduced body weight gain and increased food intake, abdominal and liver fat masses were notably increased in broilers treated with corticosterone (Bartov, 1982).

In laying hens, corticosterone causes increased feed intake, reduced weight gain, elevated corticosterone concentrations and heterophil/lymphocyte ratios, higher feather picking, longer tonic immobility, and reduced immune functions (El-lethey et al., 2001; Shini et al., 2009), in addition to increased weights of the liver and the abdominal fat pad (Pilo et al., 1985). Furthermore,

Copyright $@ 2015$ by Asian-Australasian Journal of Animal Sciences This is an open-access article distributed under the terms of the Creative Commons Attribution Non-Commercial License (http://creativecommons.org/licenses/by-nc/3.0/), which permits unrestricted non-commercial use, distribution, and reproduction in any medium, provided the original work is properly cited. 
corticosterone administration delayed the onset of egg laying and shorted the duration of peak production, thereby reduced hen day egg production (Shini et al., 2009). Remarkable reduction has been observed in the weights of the oviduct and ovary in these hens (Pilo et al., 1985; Shini et al., 2009) or in the hens subject to induced molting (Sundaresan et al., 2007). Consistent with these observations is that a large number of atretic follicles were observed in the ovary of these hens, but not in control (Mumma et al., 2006). Through these effects, corticosterone treatment may have contributed to both reduced egg mass and altered plasma steroidal hormone concentrations (Henriksen et al., 2011), perhaps thereby leading to decreased fertility and hatchability of eggs while increasing the number of early dead embryos in eggs laid by highly stress-sensitive quail hens (Schmidt et al., 2009).

Although many aspects of responses to corticosterone treatments have been to date investigated in laying hens (Pilo et al., 1985; El-lethey et al., 2001; Schmidt et al., 2009; Shini et al., 2009; Henriksen et al., 2011), little is known about how dietary corticosterone affects egg quality such as yolk colors. The objective of this study was to determine the effects of dietary corticosterone on egg quality in laying hens, with special reference to yolk colors and eggshell quality.

\section{MATERIALS AND METHODS}

\section{Animal husbandry}

Forty, 47 week-old Single Comb Brown Hy-Line Leghorn laying hens were housed in individual cages in a room with a constant ambient temperature $\left(20 \pm 2^{\circ} \mathrm{C}\right)$ and a $15 \mathrm{~h}$ light:9 h dark cycle (lights on at 06:00 h) throughout the experimental period. They had free access to a commercial layer diet (Nonghyup Feed Co., Ltd., Seoul, Korea) and tap water for the first 2 weeks as the adaptation period, at the end of which hens were divided into two groups $(n=20$ each) and provided with either control or experimental diet for the next two weeks. In order to produce the experimental diet, corticosterone (92\%, \#C2505, Sigma-Aldrich Co., St. Louis, MO, USA), dissolved completely in $100 \%$ ethanol $(2.61 \mathrm{mg} / \mathrm{mL})$, was mixed with feed using a mixer for $30 \mathrm{~min}$, consequently yielding $30 \mathrm{mg}$ corticosterone per $\mathrm{kg}$ diet. For control diet, the same amount of ethanol as one used in the experimental diet was added to the feed and was mixed for $30 \mathrm{~min}$. This procedure made no alcohol left in the diet. Feed intake and egg production were monitored daily in the morning, and body weight was measured weekly throughout the experimental period. This study was approved by the Institutional Animal Use and Care Committee of Gyeongsang National University.

\section{Egg quality}

Egg quality on days $0,1,5$, and 10 were measured within $24 \mathrm{~h}$ after the collection for egg weight, albumen height, Haugh unit (HU), shell weight, shell color, and yolk colors with QCM+ (TSS, York, England). Eggshell thickness (without the inner and outer shell membranes) was measured using a micrometer (Mitutoyo Co., Ltd., Kawasaki, Japan). Shell strength was measured using an FHK eggshell strength tester (Fugihira Industry Co., Ltd., Tokyo, Japan) by fixing the sharp edge of the egg to come down, and yolk colors were determined using a yolk color fan (BASF Co., Ltd., Monheim, Germany).

\section{Blood biochemical analysis}

At the end of the entire experiment, blood was collected into vacutainers containing heparin (\#367874, BD Co., Ltd., Franklin Lakes, NJ, USA) from the trunk of birds after decapitation with a guillotine. After the blood samples were centrifuged at $2,000 \times g$ at $4^{\circ} \mathrm{C}$ for $10 \mathrm{~min}$, plasma was decanted into new tubes which were stored at $-20^{\circ} \mathrm{C}$ until later analysis. Blood biochemicals were measured using a VetTest Chemistry Analyzer (IDEXX Co., Ltd., Westbrook, ME, USA) with a dry-slide technology. Plasma corticosterone concentrations were determined in duplicates using an ELISA kit (\#ADI-901-097, Enzo Life Sciences, Farmingdale, NY, USA).

\section{Statistical analyses}

All data were represented as mean \pm standard error of the mean. A Student's t-test was performed using Microsoft Excel to assess differences between control and corticosterone-treatment groups at $\mathrm{p} \leq 0.05$.

\section{RESULTS}

\section{Performance}

No hens were found dead through the entire experiment. Dietary corticosterone administration resulted in significant increase in feed intake by up to $39 \%$ for 14 days $(\mathrm{p}<0.05)$, but no significant changes ( $p>0.05)$ in weekly body weights, compared with control. In corticosterone-treated hens, egg production started to plunge by approximately $30 \%$ around day 5 and reached nearly $0 \%$ around day 11 whereas control maintained around 90\% (Kim and Choi, 2014).

\section{Egg quality}

Egg weight, eggshell weight, shell color and shell strength were not different ( $p>0.05$ ), but shell thickness was significantly increased by corticosterone on days 1 and 10 compared with control $(\mathrm{p}<0.05)$ (Figure 1). By corticosterone treatment, albumen height and thereby $\mathrm{HU}$ were significantly decreased in eggs produced on day 10 . 

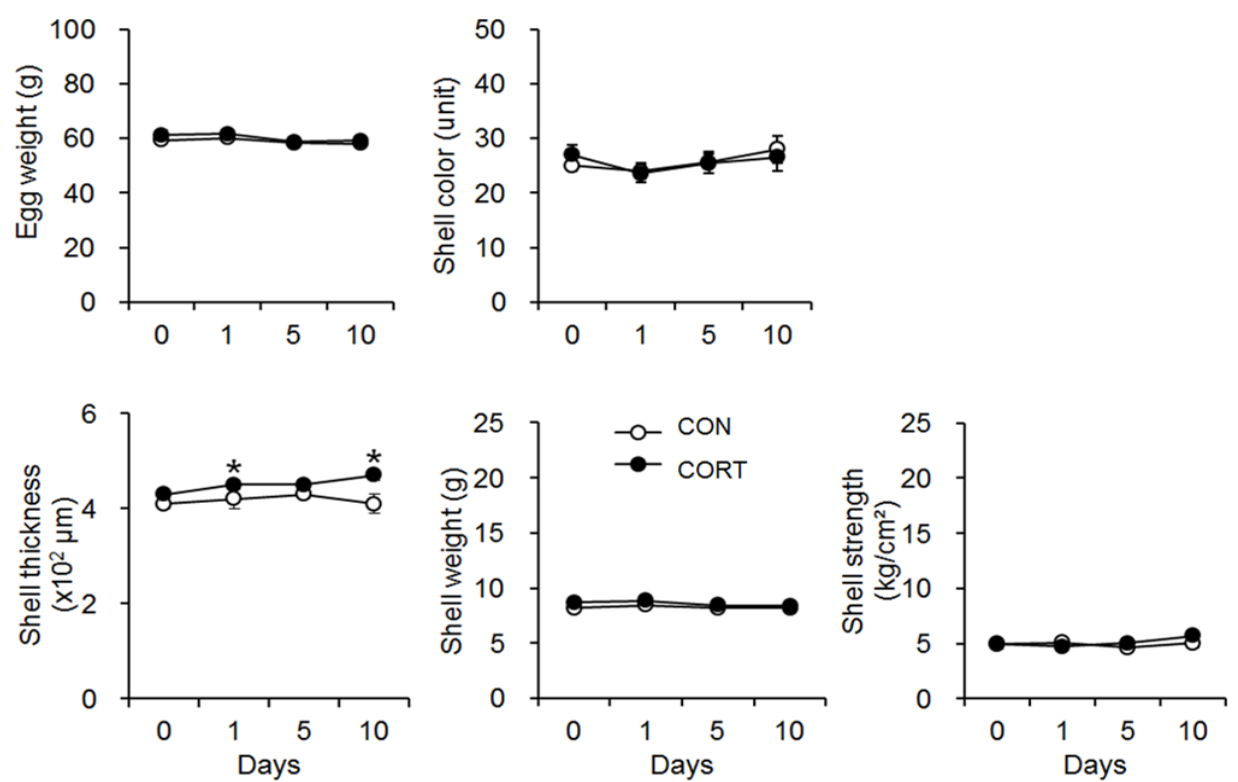

Figure 1. Effects of dietary corticosterone on egg weight, shell color, shell thickness, shell weight, and shell strength in laying hens. The birds were provided for 14 days with either control (CON) or experimental diet (CORT) containing corticosterone at $30 \mathrm{mg} / \mathrm{kg} \mathrm{diet}$. $* \mathrm{p}<0.05$. Data show means \pm standard error of the mean $(\mathrm{n}=10)$.

Significant increase in yolk colors was observed in corticosterone-treated group on days 1 and $10(\mathrm{p}<0.05)$. In particular, yolk redness was gradually increased by corticosterone over the time, reaching significant differences on days 5 and $10(\mathrm{p}<0.05)$ (Figure 2), but both yellowness and lightness were either not significantly different or inconsistent between two groups.

\section{Blood biochemical analysis}

Plasma concentrations of biochemicals are shown in Table 1. Plasma corticosterone concentrations were significantly higher in corticosterone-treated group, compared with control $(\mathrm{p}<0.05)$. Increased concentrations were found for corticosterone, glucose, cholesterol, creatinine, uric acid, albumin, aspartate aminotransferase (AST), creatine kinase (CK), lactate dehydrogenase (LDH),
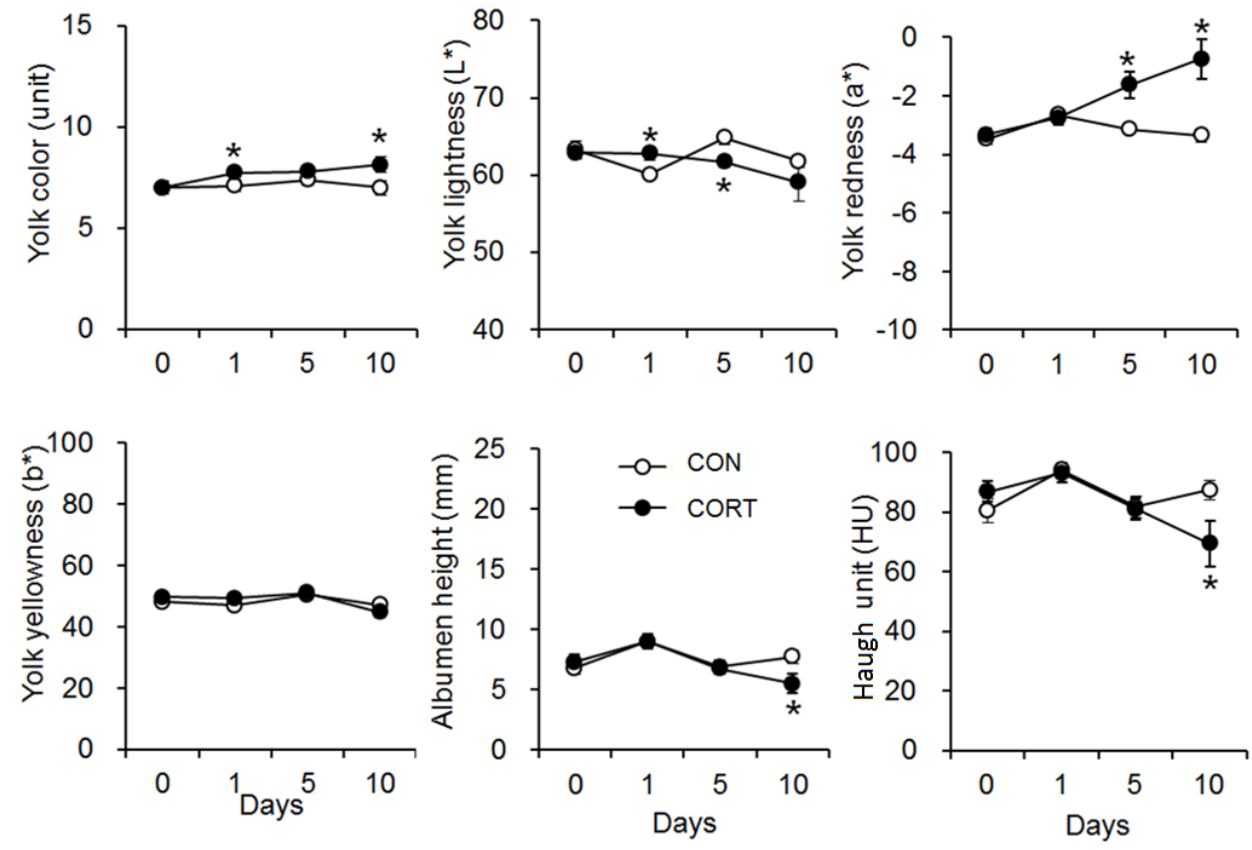

Figure 2. Effects of dietary corticosterone on yolk color, lightness $\left(\mathrm{L}^{*}\right)$, redness $\left(\mathrm{a}^{*}\right)$, yellowness $\left(\mathrm{b}^{*}\right)$, albumin height, and Haugh unit of eggs in laying hens. The birds were provided for 14 days with either control (CON) or experimental diet (CORT) containing corticosterone at $30 \mathrm{mg} / \mathrm{kg}$ diet. $* \mathrm{p}<0.05$. Data show means \pm standard error of the mean $(\mathrm{n}=10)$. 
Table 1. Effects of dietary corticosterone on plasma concentrations of corticosterone, glucose, cholesterol, triglyceride, ammonia, albumin, creatinine, globulin, total protein, uric acid, amylase, aspartate aminotransferase, creatine kinase, lactate dehydrogenase, magnesium, calcium and phosphorus in laying hens

\begin{tabular}{|c|c|c|c|}
\hline Parameters & $\mathrm{CON}$ & CORT & p-value \\
\hline Corticosterone (ng/mL) & $13.1 \pm 1.0$ & $18.3 \pm 1.2$ & 0.02 \\
\hline Glucose (mg/dL) & $260.7 \pm 6.57$ & $319.2 \pm 19.3$ & 0.005 \\
\hline Cholesterol (mg/dL) & $93.5 \pm 9.74$ & $229.2 \pm 20.4$ & 0 \\
\hline Triglyceride (mg/dL) & $365.8 \pm 7.5$ & $200.4 \pm 43.7$ & 0.001 \\
\hline Ammonia $(\mu \mathrm{mol} / \mathrm{L})$ & $139 \pm 16.6$ & $182.2 \pm 29.7$ & 0.105 \\
\hline Albumin (g/dL) & $1.6 \pm 0.16$ & $2.1 \pm 0.05$ & 0.007 \\
\hline Creatinine (mg/dL) & $0.06 \pm 0.03$ & $0.2 \pm 0.04$ & 0.012 \\
\hline Globulin (mg/dL) & $3.3 \pm 0.22$ & $3.7 \pm 0.14$ & 0.075 \\
\hline Total protein $(\mathrm{mg} / \mathrm{dL})$ & $4.9 \pm 0.30$ & $6.0 \pm 0.21$ & 0.007 \\
\hline Uric acid (mg/dL) & $5.4 \pm 0.95$ & $11.5 \pm 0.05$ & 0.001 \\
\hline Amylase (U/L) & $193.2 \pm 31.7$ & $268.5 \pm 21.42$ & 0.046 \\
\hline $\begin{array}{l}\text { Aspartate } \\
\text { aminotransferase (U/L) }\end{array}$ & $156.6 \pm 20.6$ & $262 \pm 7.6$ & 0.007 \\
\hline $\begin{array}{l}\text { Creatine kinase } \\
\left(\times 10^{3} \mathrm{U} / \mathrm{L}\right)\end{array}$ & $446.5 \pm 131.8$ & $930.5 \pm 249.1$ & 0.050 \\
\hline $\begin{array}{l}\text { Lactate dehydrogenase } \\
\left(\times 10^{3} \mathrm{U} / \mathrm{L}\right)\end{array}$ & $1,181 \pm 193$ & $2,110 \pm 423.5$ & 0.026 \\
\hline Calcium (mg/dL) & $15.5 \pm 0.39$ & $11.9 \pm 0.78$ & 0.001 \\
\hline Magnesium (mg/dL) & $3.5 \pm 0.39$ & $3.0 \pm 0.13$ & 0.152 \\
\hline Phosphorus (mg/dL) & $5.1 \pm 0.45$ & $5.3 \pm 0.54$ & 0.383 \\
\hline
\end{tabular}

Laying hens were provided for 14 days with either control (CON) or experimental diet (CORT) containing corticosterone at $30 \mathrm{mg} / \mathrm{kg}$ diet. Data show means \pm standard error of the mean $(n=8)$.

total protein (TP), and amylase in plasma of hens treated with corticosterone $(\mathrm{p}<0.05)$ while those for triglyceride and calcium were decreased $(\mathrm{p}<0.05)$. Corticosterone treatment failed to affect ammonia, phosphorus, and globulin concentrations in plasma.

\section{DISCUSSION}

The present results show that despite enhanced feed intake, which is similar to those found in previous studies (Bartov et al., 1980; Siegel and Van Kampen, 1984), dietary corticosterone did not affect body weight in laying hens. Rather, corticosterone treatments have been reported to decline body weight in broilers (Jiang et al., 2008; Yuan et al., 2008) and laying hens (El-lethey et al., 2001; Shini et al., 2009; Liu et al., 2012). Corticosterone treatments also decrease feed and caloric efficiencies (Klasing et al., 1987; Lin et al., 2006; Dong et al., 2007; Jiang et al., 2008; Yuan et al., 2008), which is associated with enhanced energy expenditure, proteolysis and gluconeogenesis (Bellamy and Leonard, 1965; Lin et al., 2004a, b). Elevated release of corticosterone from the adrenal cortex in response to stressful stimuli has been proposed to promote gluconeogenesis to increase plasma glucose concentrations and lipolysis to break down fat tissues to provide the bird with more energy (Scanes, 2009). Increased feed intake by dietary corticosterone may have been another factor contributing to changes in blood glucose and protein concentrations. But these changes are likely to be secondary, rather than primary, effect on those parameters, because although feed intake was decreased, plasma concentrations of glucose and uric acid were increased in broilers treated with dietary administration of corticosterone (Lin et al., 2004a).

Corticosterone treatments also led to decreased egg production in laying hens, and resulted in elevated concentrations of corticosterone in plasma which is associated with reduced daily egg production in hens (Koelkebeck and Cain, 1984; Shini et al., 2009) by delaying the onset of egg laying and shortening the period of peak production (Shini et al., 2009). It seems that corticosterone decreases egg production by way of affecting energy metabolism with reduced feed and calorie efficiencies (Yuan et al., 2008) and by reducing weights of the ovary and oviduct of laying hens (Shini et al., 2009).

Studies have shown that heat stress reduces egg production, egg weight, shell weight and shell thickness in laying hens (Mashaly et al., 2004; Mack et al., 2013), and similar results were found in egg-laying ducks (Ma et al., 2014). In the current study, shell thickness, but not shell weight and shell strength, was significantly increased by corticosterone compared with control, suggesting an altered structure in egg shell induced by elevated corticosterone. High plasma corticosterone concentrations play a critical role in eggshell formation depending on the time of egg laying (Klingensmith et al., 1984). Indeed, dexamethasone, a synthetic glucocorticoid, has been shown to prolong the period of egg formation and to reduce the expression of calbindin mRNA in the eggshell gland and the intestine (Bar et al., 1996) and c-myc mRNA in the oviduct (Rories et al., 1989). Expression of calbindin occurs after that of osteopontin, both of which plays a role in calcification, and soft shells are accompanied by reduced expression in calbindin, but not in osteopontin (Lavelin et al., 1998).

Corticosterone treatment altered yolk colors in the current study. Redness in yolk colors was gradually increased in eggs laid on days 5 and 10 from corticosteronetreated hens, but lightness was not consistent over the time period of measurements. These changes resulted in slight but significant increase in yolk colors. Yolk colors are affected by feed components (Roberson et al., 2005; Hammershoj et al., 2010). Mother hens regularly deposit nutrients and xanthophyll into eggs (Palmer, 1915). As corticosterone-treated hens consumed more feed, but laid eggs fewer compared with control in this study, reduced egg production by corticosterone may have contributed at least in part to enhanced redness in yolk colors. 
Corticosterone deteriorates egg freshness as shown by reduced HU in this study. HU has been used for long as an indicator of egg freshness which is expressed as relationship of egg weight and albumen height (Haugh, 1937). In the current study, corticosterone failed to affect egg weight but did decrease albumen height on day 10 , thereby resulting in reduced HU. Stress such as heat stress decreased HU in addition to egg production, egg weight, eggshell strength and eggshell thickness in laying ducks (Ma et al., 2014). However, stock density shows different effects depending upon experimental methods. Increasing stock density resulted in decreased HU but no change in shell thickness (Onbaşilar and Aksoy, 2005), or no effects on HU and shell thickness (Davami et al., 1987). Nutritional modulation of stress has been indicative of varying results: dietary betaine resulted in no changes in HU, albumen weight, and egg specific gravity but increased egg production when hens reared under high air ammonia conditions (Gudev et al., 2011). On the other hand, dietary humate decreased HU without affecting shell thickness and strength, but increased egg production, feed consumption, and feed conversion ratio when hens were housed in high density (Hayirli et al., 2005).

High plasma corticosterone concentrations appear to be associated with reduced egg quality in the current study. Effects of corticosterone on egg quality have been observed across avian species. Previous studies have reported that maternal stress can increase corticosterone content in eggs of great tits (Pitk et al., 2012), with lower maternal condition being associated with higher deposition of yolk corticosterone in European starlings (Love et al., 2008). Maternally increased corticosterone has been shown to result in female-biased hatching sex ratios caused by elevated male embryonic mortality, lighter male offspring at hatching and subsequently retarded growth during postnatal development, and lower cell-mediated immune responses in males of European starlings (Love et al., 2005). Furthermore, direct injections of corticosterone into eggs resulted in increased embryo mortality, earlier termination of fetal development, and reduced growth rates after hatching in chickens (Eriksen et al., 2003), and in greater loss of egg mass, reduced immunity and altered behavior in offspring of yellow-legged gulls (Rubolini et al., 2005). Similar results were also observed in Japanese quail showing that elevating maternal corticosterone causes reduced growth rate and abnormal behavior of their offspring (Hayward and Wingfield, 2004). As corticosterone in the blood circulation is transferred into the albumen and yolk of the eggs, corticosterone concentrations of albumen were increased in the eggs from stressed hens than control eggs in barn swallows (Saino et al., 2005) and laying hens (Downing and Bryden, 2008). Corticosterone concentrations in egg albumen has been suggested as a non- invasive indicator of stress in laying hens, as indicated by the facts that higher corticosterone concentrations in albumen can affect phenotype and embryonic development of offspring (Saino et al., 2005) and that plasma corticosterone concentrations are positively related with albumen corticosterone concentrations (Downing and Bryden, 2008). Stressed mothers lay eggs with high corticosterone levels which lead to low-quality offspring (Saino et al., 2005).

The present study shows that dietary corticosterone resulted in significant increase in glucose, cholesterol, albumin, creatinine, uric acid, amylase, AST, LDH, and TP concentrations in plasma, with the tendency to increase CK $(\mathrm{p}<0.0503)$ and globulin $(\mathrm{p}<0.075)$, and in significant decrease in triglyceride and $\mathrm{Ca}^{2+}$, but no changes in ammonia, phosphorus and magnesium. Similar results have been reported in laying hens after either adrenocorticotropic hormone (ACTH) infusion (Mumma et al., 2006) or chronic corticosterone administrations (Shini et al., 2009), and in broilers after ACTH administration (Puvadolpirod and Thaxton, 2000). In the current study, triglyceride concentrations were decreased by corticosterone, opposite to previous studies using corticosterone, heat stress or lipopolysaccharide administration (Lin et al., 2008; Shini et al., 2008).

With the TP being increased in plasma, the present results suggest that dietary corticosterone has contributed to increased protein breakdown, renal dysfunctions, and pancreatitis. An increased muscle proteolysis resulted in greater uric acid concentrations in plasma of broilers treated with dietary corticosterone (Lin et al., 2004a). Prolonged starvation also causes to increase uric acid in plasma, which is associated with increased proteolysis, plasma corticosterone, and body mass loss, but with decreased plasma $\beta$-hydroxybutyrate reflecting a decreased contribution of lipids to energy metabolism (Lumeij, 2008). Renal dysfunctions are other factors leading to elevated concentrations of plasma nonprotein nitrogen such as uric acid, creatinine and urea (Lumeij, 2008). Increased amylase and lipase activities in plasma appear to be related to pancreatitis (Keim et al., 1998; Hoffmann and Solter, 2008). Increased concentrations of enzymes such as AST, LDH, and CK have been considered as indicators of recent organ damage rather than decreased organ functions or muscle damage (Hoffmann and Solter, 2008; Lumeij, 2008).

Taken together, the results of the current study imply that dietary corticosterone affects egg quality such as yolk colors and shell thickness, in addition to its effects on feed intake and egg production.

\section{ACKNOWLEDGMENTS}

This work was supported in part by an NGB21 
(PJ008049) from the Rural Development Administration and an NRF (0004661) from the National Research Foundation of Korea, Republic of Korea.

Yeon-Hwa Kim, Jimin Kim, and Hyung-Sook Yoon were recipients of a BK21 Plus Program.

Part of this study was presented in the 25th Australian Poultry Science Symposium, Sydney, New South Wales, Australia, February 16 to 19, 2014, in "Effects of dietary corticosterone on egg production and quality in laying hens", by Y.-H. Kim, J. Kim, H.-S. Yoon, and Y.-H. Choi.

The authors are grateful to the anonymous reviewers and the Section Editor for their criticism and comments on the manuscript.

\section{CONFLICT OF INTEREST}

We certify that there is no conflict of interest with any financial organization regarding the material discussed in the manuscript.

\section{REFERENCES}

Bar, A., E. Vax, W. Hunziker, O. Halevy, and S. Striem. 1996. The role of gonadal hormones in gene expression of calbindin $(\mathrm{Mr}$ 28,000) in the laying hen. Gen. Comp. Endocrinol. 103:115122.

Bartov, I. 1982. Corticosterone and fat deposition in broiler chicks: effect of injection time, breed, sex and age. Br. Poult. Sci. 23:161-170.

Bartov, I., L. S. Jensen, and J. R. Veltmann, Jr. 1980. Effect of corticosterone and prolactin on fattening in broiler chicks. Poult. Sci. 59:1328-1334.

Bellamy, D. and R. A. Leonard. 1965. Effect of cortisol on the growth of chicks. Gen. Comp. Endocrinol. 5:402-410.

Carsia, R. V. and S. Harvey. 2000. Chapter 19. Adrenals In: Sturkie's Avian Physiology, Fifth Edn, (Ed. G. C. Whittow). Academic Press, San Diego, CA, USA. pp. 489-537.

Davami, A., M. J. Wineland, W. T. Jones, R. L. Ilardi, and R. A. Peterson. 1987. Effects of population size, floor space, and feeder space upon productive performance, external appearance, and plasma corticosterone concentration of laying hens. Poult. Sci. 66:251-257.

Delezie, E., Q. Swennen, J. Buyse, and E. Decuypere. 2007. The effect of feed withdrawal and crating density in transit on metabolism and meat quality of broilers at slaughter weight. Poult. Sci. 86:1414-1423.

Dong, H., H. Lin, H. C. Jiao, Z. G. Song, J. P. Zhao, and K. J. Jiang. 2007. Altered development and protein metabolism in skeletal muscles of broiler chickens (Gallus gallus domesticus) by corticosterone. Comp. Biochem. Physiol. Part A Mole Integr. Physiol. 147:189-195.

Downing, J. A. and W. L. Bryden. 2008. Determination of corticosterone concentrations in egg albumen: A non-invasive indicator of stress in laying hens. Physiol. Behav. 95:381-387.

El-lethey, H., T. W. Jungi, and B. Huber-Eicher. 2001. Effects of feeding corticosterone and housing conditions on feather pecking in laying hens (Gallus gallus domesticus). Physiol.
Behav. 73:243-251.

Eriksen, M. S., A. Haug, P. A. Torjesen, and M. Bakken. 2003. Prenatal exposure to corticosterone impairs embryonic development and increases fluctuating asymmetry in chickens (Gallus gallus domesticus). Br. Poult. Sci. 44:690-697.

Gudev, D., S. Popova-Ralcheva, I. Yanchev, P. Moneva, E. Petkov, and M. Ignatova. 2011. Effect of betaine on egg performance and some blood constituents in laying hens reared indoor under natural summer temperatures and varying levels of air ammonia. Bulgarian J. Agric. Sci. 17:859-866.

Hammershoj, M., U. Kidmose, and S. Steenfeldt. 2010. Deposition of carotenoids in egg yolk by short-term supplement of coloured carrot (Daucus carota) varieties as forage material for egg-laying hens. J. Sci. Food Agric. 90:1163-1171.

Haugh, R. R. 1937. A new method for determining the quality of an egg. U.S. Egg and Poult Mag 39:27-49.

Hayirli, A., N. Esenbuğa, M. Macit, E. Laçin, M. Karaoğlu, H. Karaca, and L. Yildiz. 2005. Nutrition practice to alleviate the adverse effects of stress on laying performance, metabolic profile, and egg quality in peak producing hens: I. The humate supplementation. Asian Australas. J. Anim. Sci. 18:1310-1319.

Hayward, L. S. and J. C. Wingfield. 2004. Maternal corticosterone is transferred to avian yolk and may alter offspring growth and adult phenotype. Gen. Comp. Endocrinol. 135:365-371.

Henriksen, R., T. G. Groothuis, and S. Rettenbacher. 2011. Elevated plasma corticosterone decreases yolk testosterone and progesterone in chickens: Linking maternal stress and hormone-mediated maternal effects. PloS one 6(8):e23824.

Hoffmann, W. E. and P. F. Solter. 2008. Chapter 12 - Diagnostic Enzymology of Domestic Animals. In: Clinical Biochemistry of Domestic Animals, Sixth Edn, (Eds. J. J. Kaneko, J. W. Harvey, and M. L. Bruss). Academic Press, San Diego, CA, USA. pp. 351-378.

Jiang, K. J., H. C. Jiao, Z. G. Song, L. Yuan, J. P. Zhao, and H. Lin. 2008. Corticosterone administration and dietary glucose supplementation enhance fat accumulation in broiler chickens. Br. Poult. Sci. 49:625-631.

Keim, V., N. Teich, F. Fiedler, W. Hartig, G. Thiele, and J. Mössner. 1998. A comparison of lipase and amylase in the diagnosis of acute pancreatitis in patients with abdominal pain. Pancreas. 16:45-9.

Kim, J. and Y. H. Choi. 2014. Differential abundance of egg white proteins in laying hens treated with corticosterone. J. Agric. Food Chem. 62:12346-12359.

Klasing, K. C., D. E. Laurin, R. K. Peng, and D. M. Fry. 1987. Immunologically mediated growth depression in chicks: influence of feed intake, corticosterone and interleukin-1. J Nutr 117:1629-1637.

Klingensmith, P. M., P. Y. Hester, and E. K. Wilson. 1984. Relationship of plasma corticosterone and adrenal cholesterol and corticosterone to the production of soft-shelled and shellless eggs. Poult. Sci. 63:1841-1845.

Koelkebeck, K. W. and J. R. Cain. 1984. Performance, behavior, plasma corticosterone, and economic returns of laying hens in several management alternatives. Poult. Sci. 63:2123-2131.

Lavelin, I., N. Yarden, S. Ben-Bassat, A. Bar, and M. Pines. 1998. Regulation of osteopontin gene expression during egg shell formation in the laying hen by mechanical strain. Matrix Biol. 17:615-623. 
Lin, H., D. De Vos, E. Decuypere, and J. Buyse. 2008. Dynamic changes in parameters of redox balance after mild heat stress in aged laying hens (Gallus gallus domesticus). Comp. Biochem. Physiol. Part C Toxicol. Pharmacol. 147:30-35.

Lin, H., E. Decuypere, and J. Buyse. 2004a. Oxidative stress induced by corticosterone administration in broiler chickens (Gallus gallus domesticus): 1. Chronic exposure. Comp. Biochem. Physiol. Part B Biochem. Mole Biol. 139:737-744.

Lin, H., E. Decuypere, and J. Buyse. 2004b. Oxidative stress induced by corticosterone administration in broiler chickens (Gallus gallus domesticus): 2. Short-term effect. Comp. Biochem. Physiol. Part B Biochem. Mole Biol. 139:745-751.

Lin, H., S. J. Sui, H. C. Jiao, J. Buyse, and E. Decuypere. 2006. Impaired development of broiler chickens by stress mimicked by corticosterone exposure. Comp. Biochem. Physiol. Part A Mol. Integr. Physiol. 143:400-405.

Liu, L., Z. Song, A. Sheikhahmadi, H. Jiao, and H. Lin. 2012. Effect of corticosterone on gene expression of feed intake regulatory peptides in laying hens. Comp. Biochem. Physiol. Part B Biochem. Mol. Biol. 162:81-87.

Love, O. P., E. H. Chin, K. E. Wynne-Edwards, and T. D. Williams. 2005. Stress hormones: A link between maternal condition and sex-biased reproductive investment. Am. Nat. 166:751-766.

Love, O. P., K. E. Wynne-Edwards, L. Bond, and T. D. Williams. 2008. Determinants of within- and among-clutch variation in yolk corticosterone in the European starling. Horm. Behav. 53:104-111

Lumeij, J. T. 2008. Chapter 28 - Avian Clinical Biochemistry. In: Clinical Biochemistry of Domestic Animals, Sixth Edn, (Eds. J. J. Kaneko, J. W. Harvey, and M. L. Bruss). Academic Press, San Diego, CA, USA. pp. 839-872.

Ma, X., Y. Lin, H. Zhang, W. Chen, S. Wang, D. Ruan, and Z. Jiang. 2014. Heat stress impairs the nutritional metabolism and reduces the productivity of egg-laying ducks. Anim. Reprod. Sci. 145:182-190.

Mack, L. A., J. N. Felver-Gant, R. L. Dennis, and H. W. Cheng. 2013. Genetic variations alter production and behavioral responses following heat stress in 2 strains of laying hens. Poult. Sci. 92:285-294.

Mashaly, M. M., G. L. Hendricks, 3rd, M. A. Kalama, A. E. Gehad, A. O. Abbas, and P. H. Patterson. 2004. Effect of heat stress on production parameters and immune responses of commercial laying hens. Poult. Sci. 83:889-894.

Mumma, J. O., J. P. Thaxton, Y. Vizzier-Thaxton, and W. L. Dodson. 2006. Physiological stress in laying hens. Poult. Sci. 85:761-769.

Nicol, P. C. J., S. N. Brown, E. Glen, S. J. Pope, F. J. Short, P. D. Warriss, P. H. Zimmerman, and L. J. Wilkins. 2006. Effects of stocking density, flock size and management on the welfare of laying hens in single-tier aviaries. Br. Poult. Sci. 47:135-146.

Onbaşilar, E. E. and F. T. Aksoy. 2005. Stress parameters and immune response of layers under different cage floor and density conditions. Livest. Prod. Sci. 95:255-263.

Palmer, L. S. 1915. Xanthophyll, the principal natural yellow pigment of the egg yolk, body fat, and blood serum of the hen. The physiological relation of the pigment to the xanthophyll of plants. J. Biol. Chem. 23:261-279.
Pilo, B., R. J. Etches, and J. C. George. 1985. Effects of corticosterone infusion on the lipogenic activity and ultrastructure of the liver of laying hens. Cytobios 44:273-285.

Pitk, M., V. Tilgar, P. Kilgas, and R. Mand. 2012. Acute stress affects the corticosterone level in bird eggs: A case study with great tits (Parus major). Horm. Behav. 62:475-479.

Puvadolpirod, S. and J. P. Thaxton. 2000. Model of physiological stress in chickens 1. Response parameters. Poult. Sci. 79:363369.

Roberson, K. D., J. L. Kalbfleisch, W. Pan, and R. A. Charbeneau. 2005. Effect of corn distiller's dried grains with solubles at various levels on performance of laying hens and egg yolk color. Int. J. Poult. Sci. 4:44-51.

Rories, C., C. K. Lau, K. Fink, and T. C. Spelsberg. 1989. Rapid inhibition of c-myc gene expression by a glucocorticoid in the avian oviduct. Mol. Endocrinol. (Baltimore, Md.) 3:991-1001.

Rubolini, D., M. Romano, G. Boncoraglio, R. P. Ferrari, R. Martinelli, P. Galeotti, M. Fasola, and N. Saino. 2005. Effects of elevated egg corticosterone levels on behavior, growth, and immunity of yellow-legged gull (Larus michahellis) chicks. Horm. Behav. 47:592-605.

Saino, N., M. Romano, R. P. Ferrari, R. Martinelli, and A. P. Møller. 2005. Stressed mothers lay eggs with high corticosterone levels which produce low-quality offspring. J. Exp. Zool. Part A Comp. Exp. Biol. 303:998-1006.

Scanes, C. G. 2009. Perspectives on the endocrinology of poultry growth and metabolism. Gen. Comp. Endocrinol. 163:24-32.

Schmidt, J. B., R. M. Andree, K. A. Davis, S. M. Treese, and D. G. Satterlee. 2009. Influence of maternal corticosterone treatment on incubation length of eggs laid by Japanese quail hens selected for divergent adrenocortical stress responsiveness. Br. Poult. Sci. 50:739-747.

Shini, S., P. Kaiser, A. Shini, and W. L. Bryden. 2008. Biological response of chickens (Gallus gallus domesticus) induced by corticosterone and a bacterial endotoxin. Comp. Biochem. Physiol. Part B Biochem. Mol. Biol. 149:324-333.

Shini, S., A. Shini, and G. R. Huff. 2009. Effects of chronic and repeated corticosterone administration in rearing chickens on physiology, the onset of lay and egg production of hens. Physiol. Behav. 98:73-77.

Siegel, H. S. and M. Van Kampen. 1984. Energy relationships in growing chickens given daily injections of corticosterone. $\mathrm{Br}$. Poult. Sci. 25:477-485.

Sundaresan, N. R., D. Anish, K. V. H. Sastry, V. K. Saxena, J. Mohan, and K. A. Ahmed. 2007. Cytokines in reproductive remodeling of molting White Leghorn hens. J. Reprod. Immunol. 73:39-50.

Thaxton, J. P., W. A. Dozier, 3rd, S. L. Branton, G. W. Morgan, D. W. Miles, W. B. Roush, B. D. Lott, and Y. Vizzier-Thaxton. 2006. Stocking density and physiological adaptive responses of broilers. Poult. Sci. 85:819-824.

Yuan, L., H. Lin, K. J. Jiang, H. C. Jiao, and Z. G. Song. 2008. Corticosterone administration and high-energy feed results in enhanced fat accumulation and insulin resistance in broiler chickens. Br. Poult. Sci. 49:487-495. 